\title{
Relationship of chronic endometritis with chronic deciduitis in cases of miscarriage
}

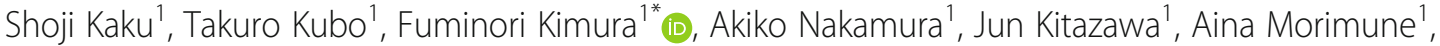 \\ Akimasa Takahashi', Akie Takebayashi ${ }^{1,2}$, Akiko Takashima', Ryoji Kushima ${ }^{3}$ and Takashi Murakami ${ }^{1}$
}

\begin{abstract}
Background: The presence of chronic deciduitis (CD) was determined in patients diagnosed with or without chronic endometritis (CE) before pregnancy.

Objective: To study the effect of CE on decidua in cases of miscarriage.

Methods: Decidual tissue was obtained from the patients who miscarried at the first pregnancy within a year after the diagnosis of the presence or absence of CE. The number and distribution pattern of plasma cells stained with CD138 in decidual tissue in 10 high-power fields (HPFs) was examined. The prevalence of CD diagnosed with four different grade; grade 0, no plasma cell in $10 \mathrm{HPFs}$, thus Non-CD;grade 1, rare single plasma cells; grade 2, rare clusters or more than 5 single cells total; and grade 3, many plasma cells with more than 5 clusters, were examined and compared between Non-CE and CE.

Results: The incidence rate of CD of grade +3 was significantly higher in CE than Non-CE $(53.8 \% ; 7 / 13$ vs. 0\%; 0 / $13, P<0.01)$. Presence of clusters or a number of plasma cells in $10 \mathrm{HPFs}$ of decidua showed a sensitivity of $53.8 \%$, a specificity of $100 \%$, a positive predictive value of $100 \%$, and a negative predictive value of $68.4 \%$ for the diagnosis of $\mathrm{CE}$.

Conclusion: Presence of clusters of plasma cells or five or more of plasma cells in decidua was found in more than half of CE, but not found in Non-CE. When CD with cluster or five or more of plasma cells is confirmed histologically in miscarriage decidual tissue, the presence of CE before the pregnancy should be suspected.
\end{abstract}

Keywords: Chronic endometritis, Chronic deciduitis, Miscarriage

\section{Background}

Chronic endometritis (CE) is a slight inflammation of the endometrium that is histologically diagnosed by the presence of plasma cells in the stroma of the endometrium [1-5]. Several recent reports have shown that $C E$ is associated with infertility, implantation failure, and habitual abortion [6-11]. In addition, it has been reported that the ongoing pregnancy rate is restored when $\mathrm{CE}$ is cured with antibiotic treatment, suggesting that the

\footnotetext{
* Correspondence: kimurafu@belle.shiga-med.ac.jp

'Department of Obstetrics and Gynecology, Shiga University of Medical Science, Seta Tsukinowa-cho, Otsu, Shiga 520-2192, Japan

Full list of author information is available at the end of the article
}

cause of $C E$ is microbial infection $[9,12-15]$. The features of the endometrium in $\mathrm{CE}$ patients include an increase in the cytotoxic NK cell ratio [16], dysfunction of decidualization [17], and an abnormal pattern of endometrial peristalsis [18], leading to infertility and implantation disorder. These physiological features before pregnancy may continue even after pregnancy and may be present in the decidua. However, so far, there has been no reports of how the endometrium of CE patients changes during pregnancy. The present study focused on chronic deciduitis (CD) for the purpose of histologically examining the effects of $\mathrm{CE}$ on the decidua. $\mathrm{CD}$ is defined as a type of long-term and slight inflammation

(c) The Author(s). 2020 Open Access This article is licensed under a Creative Commons Attribution 4.0 International License, which permits use, sharing, adaptation, distribution and reproduction in any medium or format, as long as you give appropriate credit to the original author(s) and the source, provide a link to the Creative Commons licence, and indicate if changes were made. The images or other third party material in this article are included in the article's Creative Commons licence, unless indicated otherwise in a credit line to the material. If material is not included in the article's Creative Commons licence and your intended use is not permitted by statutory regulation or exceeds the permitted use, you will need to obtain permission directly from the copyright holder. To view a copy of this licence, visit http://creativecommons.org/licenses/by/4.0/. The Creative Commons Public Domain Dedication waiver (http://creativecommons.org/publicdomain/zero/1.0/) applies to the data made available in this article, unless otherwise stated in a credit line to the data. 
of the decidua found during pregnancy [19-23]. Chronic microbial infection and immune mechanisms have been implicated as the etiology of $\mathrm{CD}[19,24,25]$. The diagnosis of CD is similar to that of CE, depending histologically on the presence of plasma cells in the decidua $[19,20]$.

In the present study, the effect of $\mathrm{CE}$ on the decidua was determined by examining for the presence of plasma cells and the incidence of $\mathrm{CD}$, using the decidual tissue of patients who became pregnant but miscarried following diagnosis with or without $\mathrm{CE}$.

\section{Methods}

This research was approved by the Ethics Committee of Shiga Medical University. Informed consent was obtained from the patients. The period of ovulation was identified by a urine ovulation test and vaginal ultrasonography, and endometrial tissue around the center of the anterior endometrium was collected with 4.5 J.A.M.W Type Uterine Curettes 5-9 days after ovulation from September 2013 to May 2018. Immunostaining with CD138 for endometrial tissue was performed according to previous reports $[17,26]$. One of the gynecologists familiar with pathology judged the presence or absence of CD138-positive plasma cells and diagnosed $\mathrm{CE}$ when one or more CD138-positive plasma cells were found in $10 \mathrm{HPFs}$ (HPF = field magnified 400 times with a microscope). Non-CE (control group) was defined when plasma cells were not found in 10 visual fields. Patient information was obtained from the medical charts. Patients who then underwent dilatation and curettage due to miscarriage of the first pregnancy within a year after the diagnosis of the presence or absence of $\mathrm{CE}$ were included in the present study. Patients who became pregnant after antibiotic treatment following the diagnosis of CE were excluded. The specimens of miscarriage tissue were immunostained with CD138 in the same manner as endometrial tissue, and the number of plasma cells in 10 HPFs of decidual tissue was counted. When one or more plasma cells were recognized in decidua, $\mathrm{CD}$ was diagnosed. $\mathrm{CD}$ was divided into four grades according to the distribution pattern and number of plasma cells in 10 HPFs: Grade 0, no plasma cell in 10 HPFs, thus Non-CD; Grade 1, 1 to 5 plasma cells in 10 HPFs; Grade 2, rare clusters or 5 to 20 plasma cells in $10 \mathrm{HPFs}$; and Grade 3, 20 or more plasma cells with more than 5 clusters in 10 HPFs. The number of plasma cells in 10 HPFs of decidual tissue and the prevalence of $\mathrm{CD}$ in patients with or without $\mathrm{CE}$ were examined. In addition, the percentage with $\mathrm{CE}$ was examined in Non$\mathrm{CD}$ and in $\mathrm{CD}$ cases.

We calculated the number of patients required for enrollment using software provided by the Department of Biostatistics, Vanderbilt University (http://biostat.mc.
vanderbilt.edu/wiki/Main/PowerSampleSize). Independent, case-control, two proportion, and Fisher's exact test were selected to measure the sample size in the section of Dichotomous. We selected 0.05 for $\alpha$ (the probability that we will falsely reject the null hypothesis), 0.8 for power $(\beta)$ (the probability of always rejecting the null hypothesis if the null hypothesis is false in the statistical hypothesis test), 0 for P0 (the probability of the outcome for a control patient in prospective studies), and 0.538 for P1 (the probability of the outcome in an experimental subject in prospective studies). When we chose 1 for $\mathrm{m}$ (the ratio of control to experimental subjects for independent prospective studies), the calculation resulted in sample sizes of 12 cases for the control group and 12 cases for the affected group. The numbers of the present study were thus adequate.

Statistical analysis was performed using Graph Pad Prism 5 (GraphPad Software Inc., La Jolla, CA). Each dataset was analyzed for a normal distribution using the Kolmogorov-Smirnov test, and Student's $t$-test or the non-parametric Mann-Whitney $U$ test was used depending on the distribution pattern. The significance of differences in the pregnancy rate, live birth rate, and miscarriage rate between the Non-CE group and the CE group was examined using Fisher's analysis. A significant difference was considered present when the $P$ value was less than 0.05 .

\section{Results}

Thirteen patients diagnosed with Non-CE became pregnant, but miscarried (Control; Non-CE group), and 13 patients who were diagnosed with $\mathrm{CE}$ and subsequently became pregnant, but miscarried (CE group) were enrolled. There were no differences in age, gravidity, parity, and gestational weeks at the time of dilatation and curettage between the Non-CE and CE groups (Table 1). The numbers of plasma cells (mean \pm standard error of the mean) in $10 \mathrm{HPFs}$ of decidual tissue were $0.54 \pm 0.24$ and $14.0 \pm 5.88(P<0.01)$ in the Non-CE and CE groups, respectively (Fig. 1a, b, c, d, Fig. 2). Grade $1 \mathrm{CD}$ was found in the Non-CE group, and Grade 1, 2, and 3 CD were found in the $\mathrm{CE}$ group (Table 1). The ratios of Grade 1 CD were $30.8 \%(4 / 13)$ and $15.4 \%(2 / 13)(P=$ $0.64)$ in the Non-CE group and $C E$ group, respectively (Table 1). Similarly, the ratios of Grade $2 \mathrm{CD}$ were $0 \%$ $(0 / 13)$ and $30.8 \%(4 / 13)(P=0.48)$, respectively, and the proportions of Grade $3 \mathrm{CD}$ were $0 \%(0 / 13)$ and $23.1 \%$ $(0 / 13)(P=0.22)$, respectively (Table 1$)$. The ratios of $C D$ when defined as Grade $1+$ Grade $2+$ Grade $3 \mathrm{CD}$ were $30.8 \%(4 / 13)$ and $69.2 \%(9 / 13)(P=0.12)$, and the rates of Grade $2+$ Grade 3 CD were $0 \%(0 / 13)$ and $53.8 \%$ (7/ 13) $(P<0.01)$ in the Non-CE group and $C E$ group, respectively (Table 1). Of these, only the rates of Grade 
Table 1 Patients' characteristics and the prevalence of CD by grade in the Non-CE and CE groups

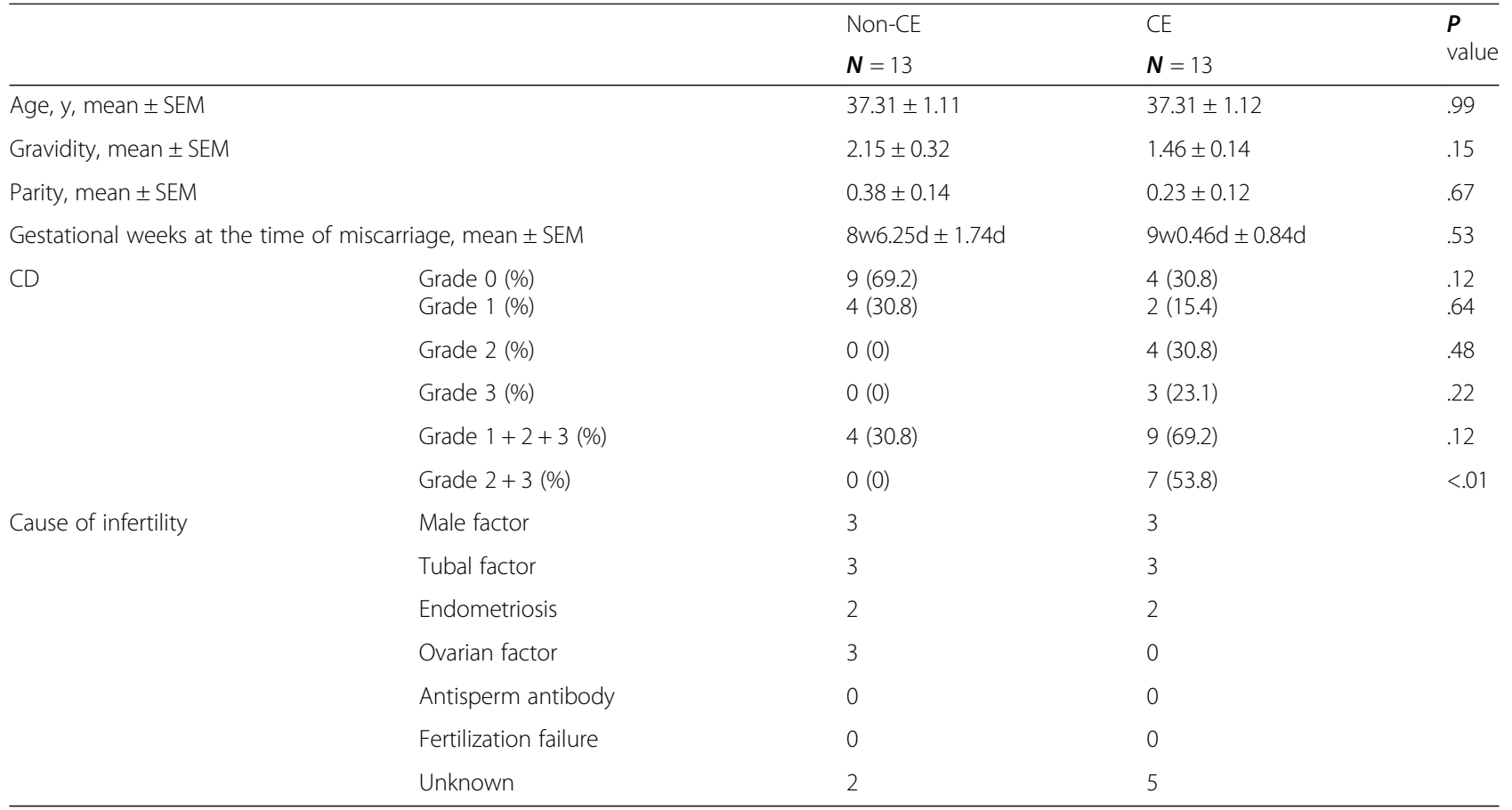

CD Chronic deciduitis, CE Chronic Endometritis, SEM Standard error of mean

$2+$ Grade 3 CD were significantly different between the two groups.

The prevalence of CE before pregnancy was examined according to the presence or absence of $\mathrm{CD}$. When $\mathrm{CD}$ was defined as the total of Grade $1+$ Grade 2 + Grade 3, the ratios of $\mathrm{CE}$ before pregnancy were $30.8 \%(4 / 13)$ and $69.2 \%(9 / 13)(P=0.12)$ in the Non-CD group and CD group. Similarly, when it was defined as Grade $2+$ Grade 3 , the ratios were $31.6 \%(6 / 19)$ and $100 \%(7 / 73)(P<$ $0.01)$, respectively. The ratios were $43.5 \%(10 / 23)$ and $100 \%(3 / 3) \quad(P=0.22)$, respectively, when it was only Grade 3.

With respect to the diagnosis of CE, Grade $2+$ Grade 3 CD showed a sensitivity of $53.8 \%$, a specificity of $100 \%$,
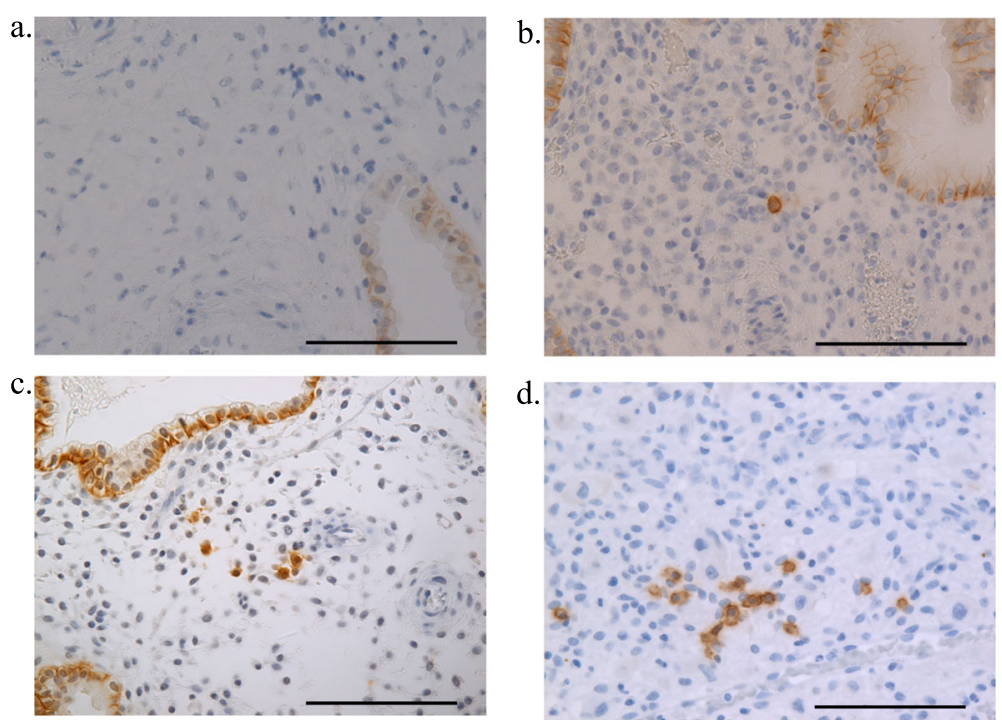

Fig. 1 Immunohistochemistry of CD138 for decidual tissue. a No cells stained with CD138 are found in Non-CD. b. Grade 1 CD, one to 5 plasma cells found in $10 \mathrm{HPFs}$. c. Grade 2 CD, rare clusters or 5 to 20 plasma cells in $10 \mathrm{HPFs}$. d. Grade 3 CD, 20 or more plasma cells with more than 5 clusters in 10 HPFs. Bar $=100 \mu \mathrm{m}$ 


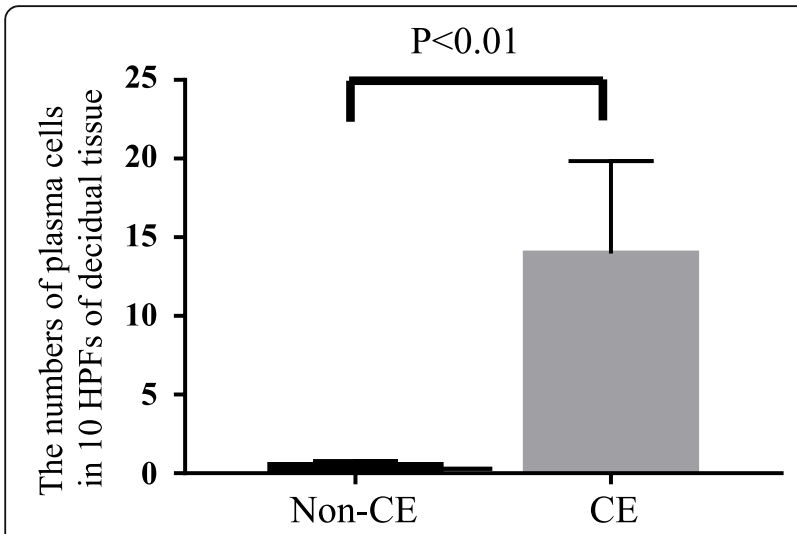

Fig. 2 The number of plasma cells in the decidual tissue in Non-CE and CE patients. The numbers of plasma cells (mean \pm standard error) in $10 \mathrm{HPFs}$ of decidual tissue is $0.52 \pm 0.17$ and $14.0 \pm 5.88(\mathrm{P}<$ 0.01 ) in Non-CE and CE patients, respectively.

a positive predictive value of $100 \%$, and a negative predictive value of $68.4 \%$.

\section{Discussion}

According to the results of the present study, CD with the presence of a cluster or a number of plasma cells was frequently found when a CE patient became pregnant and miscarried. This suggested that inflammation in the endometrium remains in the decidua of some cases of miscarriage.

$\mathrm{CD}$ is pathologically diagnosed with the presence of plasma cells within the decidua (decidual endometrium). Although studies of $\mathrm{CD}$ in preterm and/or term pregnancy have been reported $[20,23]$, there have been no reports of $\mathrm{CD}$ in early-stage pregnancy. Therefore, there are no diagnostic criteria for CD in early pregnancy. Gilmore et al. pointed out that the histologic diagnostic criteria for CE differ from the literature and used a semiquantitative scoring system to avoid these problems [27]. They divided the status into 4 grades: grade 0 , no plasma cells seen; grade 1 , rare single plasma cells; grade 2 , rare clusters or more than 5 single cells total; and grade 3 , many plasma cells with more than 5 clusters. In the present study, $\mathrm{CD}$ for the specimens of miscarriage cases was classified based on the report by Gilmore et al. That is, Non CD was defined as no plasma cells seen, and $\mathrm{CD}$ was divided into 3 grades: grade 1,1 to 5 plasma cells in $10 \mathrm{HPFs}$; grade 2, rare clusters or 5 to 20 plasma cells in $10 \mathrm{HPFs}$; and grade 3, 20 or more plasma cells with more than 5 clusters in 10 HPFs. It was found that there were no significant differences in the incidence of CD of Grade 1, Grade 2, Grade 3, or Grade $1+$ Grade $2+$ Grade 3 between the Non-CE and CE groups. However, there was a significant difference in the incidence of Grade $2+$ Grade $3 \mathrm{CD}$. In addition, although the number of cases was small in this study, Grade 2 or
Grade $3 \mathrm{CD}$ was not seen at all in Non-CE patients. In general, the number of immune cells per area is considered to be correlated with the degree of histological inflammation. Thus, our results suggested CD with moderate or higher inflammation was observed only in CE patients.

The association between $\mathrm{CE}$ and habitual abortion has been reported $[8,10]$. Considering these clinical data and the fact that there is a higher incidence of $\mathrm{CD}$ when $\mathrm{CE}$ patients miscarry, $\mathrm{CD}$ appears to be related to miscarriage.

Plasma cells, which are the basis of the diagnosis of $\mathrm{CD}$, produce the antibody for some kind of antigen. In patients diagnosed with $C D$ in the present study, maternal immunity may have reacted to the chorionic tissue (placental tissue) as an antigen during the course of miscarriage. Grade $1 \mathrm{CD}$ was found in 4/13 Non-CE patients who miscarried. Such a histologically mild degree of $\mathrm{CD}$ may have been due to miscarriage.

In the total cases of Grade 2 and Grade $3 \mathrm{CD}$, the incidence of $\mathrm{CE}$ before the pregnancy was 100\%. Thus, when Grade 2 or Grade $3 \mathrm{CD}$ is found in the miscarriage tissue, it means that $\mathrm{CE}$ existed before pregnancy in all cases, although the number of samples was low in the present study. Specimens from miscarriage cases have been used to confirm the presence of chorionic tissue and the exclusion of chorionic diseases such as molar pregnancy. If specimens obtained from a patient who miscarried are examined for the presence of $\mathrm{CD}$, this may provide a clue regarding the presence of $\mathrm{CE}$ before the pregnancy, which may be useful for the subsequent fertility treatment.

To the best of our knowledge, this is the first study in the world to study the relationship between $\mathrm{CE}$ and $\mathrm{CD}$ in miscarriage specimens in order to investigate the direct effects of CE on pregnancy. Currently, when diagnosed as CE, the patient is usually treated with antibiotics and then undergoes embryo transfer. When the present study was conducted, it was already beginning to be thought that antibiotics might be effective to improve clinical outcomes. The patients in the CE group extracted for the present study were those who did not want antibiotic treatment. In this sense, the cases who became pregnant but miscarried following their diagnosis with or without $\mathrm{CE}$ are few and extremely valuable. Furthermore, the miscarriage specimens of these patients were even more valuable, and the results of the analysis of the miscarriage specimens could be compared with the presence or absence of CE. This is the strength of the present study.

On the other hand, although the numbers of cases and controls satisfied the power analysis, they were relatively small. Patients who sought antibiotic treatment were treated with them and excluded from the study. Though 
this attitude is ethically correct, this means that the CE group did not reflect all CE patients in the study period. These are the limitations of the present study.

In the future, it is important to investigate the effects of antibiotic treatment for $\mathrm{CE}$ on the incidence of $\mathrm{CD}$ in this area of research. In addition, conversely, it is very important to study whether a patient diagnosed with $C D$ in a miscarriage will subsequently be diagnosed with $\mathrm{CE}$.

We hope that this research provides new insights into the relationships among $\mathrm{CE}, \mathrm{CD}$, and miscarriage.

\section{Conclusions}

Histopathological analysis of specimens from cases of miscarriage showed clusters of plasma cells or five or more plasma cells found in the decidua in more than half of CE patients, whereas they were not found in Non-CE patients. This suggests that the effect of CE remains in the decidua during pregnancy. In addition, when the presence of a plasma cell cluster or five or more of plasma cells in $10 \mathrm{HPFs}$ is confirmed histologically, the presence of $\mathrm{CE}$ before the pregnancy should be suspected. The analysis of the presence of $C D$ in the specimens of miscarriage may help subsequent fertility treatment.

\section{Abbreviations}

CD: Chronic deciduitis; CE: Chronic endometritis; HPF: high-power fields; NK cell: Natural killer cell

\section{Acknowledgements}

Nothing to disclose.

\section{Capsule}

The effect of chronic endometritis remains in the decidua of more than half of miscarriage cases, which are considered to be chronic deciduitis with a cluster or a number of plasma cells.

\section{Authors' contributions}

Conception and design: FK; contributed reagents/materials/analysis tools: SK, FK, AN, JK, AM, AT, AT, AT; performing the experiment: SK, TK, RK; analyzed the data: SK, FK; drafting the manuscript: FK. final approval of the version: RK, TM. All authors read and approved the final manuscript.

\section{Funding}

The Grants-in-Aid for Scientific Research of Japan Society for the Promotion of Science, Grant Number 16 K11083 and 19 K09752. (to F.K.).

\section{Availability of data and materials}

We can provide the raw data. The datasets used and/or analyzed during the current study available from the corresponding author on reasonable request.

\section{Ethics approval and consent to participate}

This research was approved by the Ethics Committee of Shiga University of Medical Science (IRB-ethics committee approval number, R2014-090).

\section{Consent for publication}

Informed written consent was obtained for publication.

\section{Competing interests}

No author has any conflict of interest to disclose.

\section{Author details}

'Department of Obstetrics and Gynecology, Shiga University of Medical Science, Seta Tsukinowa-cho, Otsu, Shiga 520-2192, Japan. ${ }^{2}$ Department of Obstetrics and Gynecology, National Hospital Organization Shiga Hospital, 255 Gochi-cho, Higashioumi, Shiga 527-8505, Japan. ${ }^{3}$ Department of Clinical Laboratory Medicine and Division of Diagnostic Pathology, Shiga University of Medical Science, Seta Tsukinowa-cho, Otsu, Shiga 520-2192, Japan.

Received: 17 January 2020 Accepted: 26 May 2020

Published online: 01 June 2020

\section{References}

1. Greenwood SM, Moran JJ. Chronic endometritis: morphologic and clinical observations. Obstet Gynecol. 1981;58:176-84.

2. Bayer-Garner IB, Korourian S. Plasma cells in chronic endometritis are easily identified when stained with syndecan-1. Mod Pathol. 2001;14:877-89.

3. Smith M, Hagerty KA, Skipper B, Bocklage T. Chronic endometritis: a combined histopathologic and clinical review of cases from 2002 to 2007. Int J Gynecol Pathol. 2010;29:44-50.

4. Kitaya K, Yasuo T. Immunohistochemistrical and clinicopathological characterization of chronic endometritis. Am J Reprod Immunol. 2011;66: 410-5.

5. Kimura F, Takebayashi A, Ishida M, Nakamura A, Kitazawa J, Morimune A, et al. Review: chronic endometritis and its effect on reproduction. J Obstet Gynaecol Res. 2019;45:951-60.

6. Kasius JC, Fatemi HM, Bourgain C, Sie-Go DM, Eijkemans RJ, Fauser BC, et al. The impact of chronic endometritis on reproductive outcome. Fertil Steril. 2011;96:1451-6.

7. Johnston-MacAnanny EB, Hartnett J, Engmann LL, Nulsen JC, Sanders MM, Benadiva CA. Chronic endometritis is a frequent finding in women with recurrent implantation failure after in vitro fertilization. Fertil Steril. 2010;93. 437-41.

8. McQueen DB, Bernardi LA, Stephenson MD. Chronic endometritis in women with recurrent early pregnancy loss and/or fetal demise. Fertil Steril. 2014; 101:1026-30.

9. Cicinelli E, Matteo M, Tinelli R, Lepera A, Alfonso R, Indraccolo U, et al. Prevalence of chronic endometritis in repeated unexplained implantation failure and the IVF success rate after antibiotic therapy. Hum Reprod. 2015; 30:323-30.

10. Bouet PE, El Hachem H, Monceau E, Gariépy G, Kadoch IJ, Sylvestre C. Chronic endometritis in women with recurrent pregnancy loss and recurrent implantation failure: prevalence and role of office hysteroscopy and immunohistochemistry in diagnosis. Fertil Steril. 2016;105:106-10.

11. McQueen DB, Perfetto CO, Hazard FK, Lathi RB. Pregnancy outcomes in women with chronic endometritis and recurrent pregnancy loss. Fertil Steril. 2015;104:927-31.

12. Yang $R$, Du X, Wang Y, Song X, Yang Y, Qiao J. The hysteroscopy and histological diagnosis and treatment value of chronic endometritis in recurrent implantation failure patients. Arch Gynecol Obstet. 2014;289:1363-9.

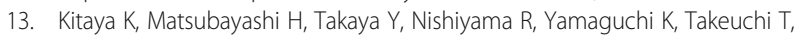
et al. Live birth rate following oral antibiotic treatment for chronic endometritis in infertile women with repeated implantation failure. Am J Reprod Immunol. 2017;78:e12719

14. Cicinelli E, Matteo M, Trojano G, Mitola PC, Tinelli R, Vitagliano A, et al. Chronic endometritis in patients with unexplained infertility: Prevalence and effects of antibiotic treatment on spontaneous conception. Am J Reprod Immunol. 2018;79:e12782.

15. Vitagliano A, Saccardi C, Noventa M, Di Spiezio SA, Saccone G, Cicinelli E, et al. Effects of chronic endometritis therapy on in vitro fertilization outcome in women with repeated implantation failure: a systematic review and meta-analysis. Fertil Steril. 2018;110:103-12.

16. Di Pietro C, Cicinelli E, Guglielmino MR, Ragusa M, Farina M, Palumbo MA, et al. Altered transcriptional regulation of cytokines, growth factors, and apoptotic proteins in the endometrium of infertile women with chronic endometritis. Am J Reprod Immunol. 2013;69:509-17.

17. Wu D, Kimura F, Zheng L, Ishida M, Niwa Y, Hirata K, et al. Chronic endometritis modifies decidualization in human endometrial stromal cells. Reprod Biol Endocrinol. 2017;15:16

18. Pinto V, Matteo M, Tinelli R, Mitola PC, De Ziegler D, Cicinelli E. Altered uterine contractility in women with chronic endometritis. Fertil Steril. 2015; 103:1049-52. 
19. Riaz N, Wolden SL, Gelblum DY, Eric J. Chronic inflammation of the placenta: definition, classification, pathogenesis, and clinical significance. Am J Obstet Gynecol. 2016;1 18:6072-8.

20. Edmondson N, Bocking A, Machin G, Rizek R, Watson C, Keating S. The prevalence of chronic Deciduitis in cases of preterm labor without clinical Chorioamnionitis. Pediatr Dev Pathol. 2009;12:16-21.

21. Khong YEE, Robert W, Qureshi F, Raymond W, Gould S, Stallmach T, et al. Chronic Deciduitis in the placental basal plate : definition and Interobserver reliability first round of assessment. Hum Pathol. 2000;31:292-5.

22. Bendon RW, Miller M. Routine pathological examination of placentae from abnormal pregnancies. Placenta. 1990;11:369-70.

23. Salafia CM, Vogel CA, Vintzileos AM, Bantham KF, Pezzullo J, Silberman L. Placental pathologic findings in preterm birth. Am J Obstet Gynecol. 1991; 165:934-8.

24. Perni SC, Predanic M, Cho JE, Baergen RN. Placental pathology and pregnancy outcomes in donor and non-donor oocyte in vitro fertilization pregnancies. J Perinat Med. 2005;33:27-32.

25. Gundogan F, Bianchi DW, Scherjon SA, Roberts DJ. Placental pathology in egg donor pregnancies. Fertil Steril. 2010;93:397-404.

26. Takebayashi A, Kimura F, Kishi Y, Ishida M, Takahashi A, Yamanaka A, et al. The association between endometriosis and chronic endometritis. PLOS One. 2014:9:e88354.

27. Gilmore H, Fleischhacker $D$, Hecht JL. Diagnosis of chronic endometritis in biopsies with stromal breakdown. Hum Pathol. 2007;38:581-4.

\section{Publisher's Note}

Springer Nature remains neutral with regard to jurisdictional claims in published maps and institutional affiliations.

Ready to submit your research? Choose BMC and benefit from:

- fast, convenient online submission

- thorough peer review by experienced researchers in your field

- rapid publication on acceptance

- support for research data, including large and complex data types

- gold Open Access which fosters wider collaboration and increased citations

- maximum visibility for your research: over $100 \mathrm{M}$ website views per year

At $\mathrm{BMC}$, research is always in progress.

Learn more biomedcentral.com/submissions 